\title{
Short-term effects of pesticide fipronil on behavioral and physiological endpoints of Daphnia magna
}

\author{
Adam Bownik $^{1}$ (D) Aleksandra Szabelak ${ }^{1}$ \\ Received: 18 November 2020 / Accepted: 17 February 2021 / Published online: 26 February 2021 \\ (C) The Author(s) 2021
}

\begin{abstract}
Fipronil (FIP) is an organic pesticide with many practical uses. Although some results indicated toxic effects in some terrestrial and aquatic animal species, little is known on its influence on behavioral and physiological endpoints of cladocerans. The aim of our study was to determine the short-term effects of FIP at concentrations of $0.1 \mu \mathrm{g} / \mathrm{L}, 1 \mu \mathrm{g} / \mathrm{L}, 10 \mu \mathrm{g} / \mathrm{L}$, and $100 \mu \mathrm{g} / \mathrm{L}$ on Daphnia magna sublethal indices: behavioral (swimming speed, distance traveled) and physiological endpoints (heart rate, postabdominal claw activity and thoracic limb movements). The results showed that FIP induced reduction of swimming speed and distance traveled in a concentration- and time-dependent manner at all the concentrations used. The lowest concentration of the insecticide temporarily stimulated post-abdominal claw activity after $24 \mathrm{~h}$ and thoracic limb activity after $48 \mathrm{~h}$; however, the highest concentrations reduced all the studied physiological endpoints. IC50 values showed that thoracic limb activity, swimming speed, and distance traveled were most sensitive to FIP after 24-h exposure. The most sensitive parameter after $48 \mathrm{~h}$ and $72 \mathrm{~h}$ was swimming speed and post-abdominal claw activity, respectively. The study indicated that (i) behavioral and physiological endpoints of Daphnia magna are reliable and valuable sublethal indicators of toxic alterations induced by FIP; however, they respond with different sensitivity at various times of exposure, (ii) FIP may alter cladoceran behavior and physiological processes at concentrations detected in the aquatic environment; therefore, it should be considered as an ecotoxicological hazard to freshwater cladocerans.
\end{abstract}

Keywords Behavior · Crustacean · Insecticides · Motility $\cdot$ Physiological activity

\section{Introduction}

Fipronil (FIP), a derivative of phenylpyrazole, is one of the most widely used organic pesticides in agriculture, veterinary medicine, and urban households for selective elimination of insect pests such as ants, mosquitos, termites, cockroaches, spiders, fleas, and mites (Tomlin 1994; Aajoud et al. 2003; Scarampella et al. 2005; Gunasekara et al. 2007; MacLachlan 2008; Simon-Delso 2014; Ardeshir et al. 2017; Rust 2017). The mechanism of FIP toxicity is, unlike most of commonly used insecticides, blocking the receptors responsible for

Responsible Editor: Bruno Nunes

Adam Bownik

adam.bownik@up.lublin.pl

1 Department of Hydrobiology and Protection of Ecosystems, University of Life Sciences in Lublin, Dobrzańskiego 37, 20-262 Lublin, Poland binding $\gamma$-aminobutyric acid (GABA) and glutamic acid of the chlorine channels ions located in the nerve cells and, as a consequence, inducing the overexcitation of the nervous system leading to paralysis, and finally death (Hossie et al. 1995; Bloomquist 2003; Gunasekara et al. 2007). Blocking of chlorine channels is much more effective in insects than in vertebrates (Bonmatin et al. 2015); therefore, FIP is assumed to be more toxic to insects than mammals.

Massive use of FIP for veterinary purposes led to hazardous incidents. Eradication of red mites in poultry farms in European countries and Japan (Van Poucke et al. 2016; Hatta et al. 2019) induced transfer of FIP to hen tissues and eggs (European Food Safety Authority (EFSA) et al. 2018; Charalampous et al. 2019). The presence of FIP in food is especially important for human health as this pesticide was classified by the US EPA as a group C (possible human) carcinogen (Charalampous et al. 2019). Because of wide application of FIP in agriculture, it is detected in terrestrial, marine, and water environments (Ngim and Crosby 2001; Bonmatin et al. 2015). FIP is a stable compound with half- 
life exceeding 100 days at a temperature of $25^{\circ} \mathrm{C}$, and it may be easily transferred to surface water (Bonmatin et al. 2015). Fipronil is stable to hydrolysis at $\mathrm{pH} 5.5$ and $\mathrm{pH} 7$, but at $\mathrm{pH}$ 9, its hydrolytic half-life is 28 days (Macbean 2012). This pesticide has been detected in various aquatic ecosystems such as estuaries, urban waterways, and lakes (Ensminger et al. 2013; Weston and Lydy 2014; Wu et al. 2015) in the range of 0.5$10.004 \mu \mathrm{g} / \mathrm{L}$ (Gan et al. 2012; Ruby 2013; Wu et al. 2014; Michel et al. 2016). The presence of FIP and its sulfone and sulfide metabolites was detected in urban streams in several states of the USA (Demcheck and Skrobialowski 2003). For example, in the USA, FIP was found at a concentration of $0.117 \mu \mathrm{g} / \mathrm{L}$ in Louisiana, while the levels of its metabolites FIP-sulfone, FIP-sulfide, FIP-desulfinyl, and FIP-amide were $0.038 \mu \mathrm{g} / \mathrm{L}$ (Colorado), $0.015 \mu \mathrm{g} / \mathrm{L}$, (Louisiana), $0.158 \mu \mathrm{g} / \mathrm{L}$ (California), and $0.011 \mu \mathrm{g} / \mathrm{L}$ (Louisiana), respectively (US Geological Survey 2006). In the runoff water of California, FIP was found at the range of $204-1170 \mathrm{ng} / \mathrm{L}$ (Gan et al. 2012). The above-mentioned levels found in aquatic environments exceed the acute and chronic aquatic life benchmark concentrations of FIP $(0.1 \mu \mathrm{g} / \mathrm{L}$ and $0.01 \mu \mathrm{g} / \mathrm{L}$, respectively) in water suggested by the US EPA (Stone et al. 2014).

A number of studies showed various detrimental effects induced by FIP in terrestrial non-target insects such as honeybees and midges (Apenet 2011; Holder et al. 2018; Monteiro et al. 2019). It was indicated that this pesticide inhibits feeding activity of dragonflies (Jinguji et al. 2018). Other terrestrial animals such as earthworms, amphibians, rabbits, and certain groups of gallinaceous birds were also reported to be affected by FIP (Pisa et al. 2015).

Since FIP is transferred to water reservoirs, it is available to aquatic biota. Degradation products of FIP may have higher toxicity, and they may be more stable than FIP itself Gunasekara et al. 2007; Tingle et al. 2003). Environmental conditions such as sunlight, acidity, temperature, microbial community composition, and presence of additional substances may modulate the overall toxicity of FIP in aquatic ecosystems (Bonmatin et al. 2015). It was noted that in increased salinity, FIP and its photodegradation products such as desulfinyl metabolite may be more bioavailable to benthic organisms (Goff et al. 2017); therefore, marine organisms should be considered as particularly susceptible to intoxication. Various effects induced by FIP were found in aquatic vertebrates and invertebrates (Schlenk et al. 2001; Wirth et al. 2004; Pisa et al. 2015; Gibbons et al. 2015; Charalampous et al. 2019). Some authors indicated that this compound is highly toxic to zebrafish larvae (Xu et al. 2018; Park et al. 2020) and a fish species Aristichthys nobilis, possibly due to high affinity of GABA receptors (Zhang et al. 2018). In zebrafish embryos, larvae and adults adverse changes of behavioral parameters and oxidative stress were also found (Stehr et al. 2006; Bevilaqua et al. 2020). FIP also induces toxic effects in marine and freshwater crustaceans such as estuarine copepod Amphiascus tenuiremis (Chandler et al. 2004), kuruma prawn, sand shrimp, and a surrogate mysid species Americamysis bahia (Hano et al. 2019), blue crab Callinectes sapidus (Goff et al. 2017), juvenile brown shrimp Farfantepenaeus aztecus (AlBadran et al. 2018), and grass shrimp Palaemonetes pugio (Key et al. 2003).

Daphnia sp. is a keystone freshwater crustacean playing many important ecological roles. They are filter feeders regulating the number of various microorganisms such as algae, cyanobacteria, protozoans, and small particles suspended in water reservoirs (Stollewerk 2010). Moreover, they are a food source for some predator species. Daphnids are also a common model organism used in acute and chronic toxicity tests (Zhang et al. 2016). Most of the available studies on the effects of FIP on cladocerans deal with determination of lethality and immobilization of model daphnids (Konwick et al. 2005; Stark and Vargas 2005; Hayasaka et al. 2012). However, detection of sublethal alterations induced by FIP may require more sensitive endpoints. Currently, novel approaches using reliable and early indicators such as behavioral (e.g., swimming speed) and physiological endpoints (e.g., heart rate, thoracic limb activity) have been introduced in ecotoxicological testing. Scientific literature indicates that alterations of these parameters may be detected much earlier before the experimental organisms are immobilized or killed (Huang et al. 2017, 2018; Bownik 2017; Bownik et al. 2020a). Therefore, the aim of our study was to investigate whether FIP affects behavioral (swimming speed and distance traveled) and physiological endpoints (the heart rate, postabdominal claw activity, and thoracic limb activity) of Daphnia magna.

\section{Material and methods}

\section{Animal culture and FIP preparation}

Daphnia magna were obtained from a single mother hatched from a dormant egg according to the procedure by Microbiotest (Belgium) (Persoone et al. 2009). The animals were cultured in $5 \mathrm{~L}$ of medium at a temperature of $23 \pm 2^{\circ} \mathrm{C}$, under light/dark period of 16:8 h. The medium was prepared in accordance with ASTM standards (American Society of Testing and Materials 1986). The animals were fed once daily with a few drops of powdered Spirulina $(2 \mathrm{mg} / \mathrm{L}$ water) per tank and supplemented with a few drops of baker's yeast (10 $\mathrm{mg} / \mathrm{L}$ per tank).

FIP (analytical standard, of $>97 \%$ purity) was purchased from Merck, and the following series of its nominal concentrations was prepared: $0.1 \mu \mathrm{g} / \mathrm{L}, 1 \mu \mathrm{g} / \mathrm{L}, 10 \mu \mathrm{g} / \mathrm{L}$, and 100 $\mu \mathrm{g} / \mathrm{L}$. Initially, the stock solution $(100 \mathrm{mg} / \mathrm{L})$ was prepared by diluting $10 \mathrm{mg}$ of FIP in the $100 \mathrm{~mL}$ of filtered culture 
medium containing $0.1 \%$ of methanol. After mixing the flask with the stock solution, the highest FIP working concentration of $100 \mu \mathrm{g} / \mathrm{L}$ was prepared by transferring $100 \mu \mathrm{L}$ of the stock solution to a volumetric flask containing $99.9 \mathrm{~mL}$ of clean culture medium. The experimental concentration of $10 \mu \mathrm{g} / \mathrm{L}$ was done by transferring $10 \mathrm{~mL}$ from the flask with $100 \mu \mathrm{g} / \mathrm{L}$ of FIP to another volumetric flask containing $90 \mathrm{~mL}$ of clean medium. A concentration of $1 \mu \mathrm{g} / \mathrm{L}$ was prepared by transferring $10 \mathrm{~mL}$ from the flask containing $10 \mu \mathrm{g} / \mathrm{mL}$ of FIP to another flask with $90 \mathrm{~mL}$ of clean medium. A concentration of $0.1 \mu \mathrm{g} / \mathrm{L}$ was prepared by transferring $10 \mathrm{~mL}$ from the flask containing FIP at $1 \mu \mathrm{g} / \mathrm{mL}$ to another flask with $90 \mathrm{~mL}$ of clean medium. The appropriate solutions of the insecticide prepared in the above-mentioned flasks were transferred at a volume of $8 \mathrm{~mL}$ to glass Petri dishes ( $75 \mathrm{~mm}$ of diameter). Each studied endpoint was examined at $24 \mathrm{~h}, 48 \mathrm{~h}$, and $72 \mathrm{~h}$ of the exposure. Animals were considered as dead when no heart activity was noted under microscopic examination.

\section{Swimming speed and distance traveled}

Each experimental group consisted of 15 neonates grouped into 5 individuals placed in three glass Petri dishes (for three independent treatments) with a diameter of $75 \mathrm{~mm}$ containing one of FIP concentrations of $0.1 \mu \mathrm{g} / \mathrm{L}, 1 \mu \mathrm{g} / \mathrm{L}, 10 \mu \mathrm{g} / \mathrm{L}$, and $100 \mu \mathrm{g} / \mathrm{L}$. Additionally, 15 animals grouped into 5 individuals placed in three experimental dishes with medium only were treated as the control. Daphnids were left 15 min for acclimation (Bownik and Pawlik-Skowrońska 2019). Horizontal swimming was recorded for $1 \mathrm{~min}$ in each Petri dish (starting from the animals exposed to the highest concentration of FIP) with a digital camera Nikon D3100 mounted on a stable stand (Bownik et al. 2019a, b, 2020a) at $24 \mathrm{~h}, 48 \mathrm{~h}$, and $72 \mathrm{~h}$ of exposure. The recorded video files were then analyzed by frame-by-frame method with Tracker® 5.1.3 computer software. The swimming tracks of a single animal were recorded by clicking the cursor on the daphnid image in the separate frames of the video clip. The swimming tracks (interpreted by the program as a mass point) were plotted on the screen, and the mean speed (v) was calculated by the software and expressed in millimeters per second $(\mathrm{mm} / \mathrm{s})$. Distances traveled by the individuals were also calculated by Tracker® 5.1.0 software after matching the swimming trails.

\section{Determination of physiological endpoints}

Heart rate, post-abdominal claw activity, and thoracic limb movement were determined by a microscopic method supported by previously described digital video analysis (Campbell et al. 2004; Bownik et al. 2019a, b, 2020b). Briefly, individual daphnids were gently transferred with a Pasteur pipette in about $50-\mu \mathrm{L}$ drop from each experimental Petri dish or the control group to a microscope slide for the microscopic analysis. The microscopic view of the examined daphnid was recorded for at least $1 \mathrm{~min}$ (with the speed of 30 frames per second) with a digital camera Nikon D3100 mounted on a light microscope. The magnification $(\times 30$ $100)$ and camera resolution allowed performing the analysis with a good visibility of the heart. The physiological endpoints were calculated with a frame-by-frame method supported by a video player by counting the number of beats (heart and thoracic limbs) or movements (post-abdominal claw) per $1 \mathrm{~min}$.

\section{Determination of IC50}

Effective (nominal) concentration (EC50) for immobilization and inhibition (nominal) concentration (IC50) for swimming speed, distance traveled, heart rate, thoracic limb activity, and post-abdominal claw activity after $24 \mathrm{~h}, 48 \mathrm{~h}$, and $72 \mathrm{~h}$ of exposure were calculated using probit regression analysis with MedCalc 19.3.1 statistical software (MedCalc-version 19.3.1. MedCalc Ltd.). Maximum log likelihood estimation (null model -2 Log likelihood, full model -2 Log likelihood) was used as an overall fit model, and logarithmic curve was plotted as a result.

\section{Statistical analysis}

Data were analyzed with statistical software Statistica® ${ }^{\circledR}$ 13.1. Normality and homogeneity of variances were estimated by the Shapiro-Wilk and Levene's tests, respectively. The tests were parametric with homogenous data. The comparisons of means among the experimental groups were done by two-way ANOVA (interactions: concentrations, time and time*concentration) followed by Dunnett's post hoc test to calculate significant differences between the experimental groups and the control. Results were significant when $p<$ 0.05 . The results are presented as means \pm standard deviation (SD).

\section{Results}

\section{EC50 and IC50 for Daphnia magna endpoints}

Calculation of nominal IC50 of the studied endpoints revealed that the most sensitive endpoints after 24-h exposure to FIP were thoracic limb activity (IC50 $=2.8 \pm 0.7 \mu \mathrm{g} / \mathrm{L}$ ) (Table 1 ; Fig. 1), swimming speed $(3.5 \pm 0.2 \mu \mathrm{g} / \mathrm{L})$, and distance traveled $(3.3 \pm 0.2 \mu \mathrm{g} / \mathrm{L})$. Heart rate was the least sensitive indicator $(708 \pm 27 \mu \mathrm{g} / \mathrm{L})$; however, its EC50 value after 72 -h exposure was similar to those of the behavioral endpoints. EC50 for daphnid immobilization showed the lowest sensitivity after $72 \mathrm{~h}$ of exposure $(0.5 \pm 0.04 \mu \mathrm{g} / \mathrm{L})$. 
Table 1 Nominal EC50 values ( $\mu \mathrm{g} / \mathrm{L})$ for immobilization and IC50 values $(\mu \mathrm{g} / \mathrm{L})$ for the studied behavioral and physiological endpoints of Daphnia magna after 24-h, 48-h, and 72-h exposure to fipronil

\begin{tabular}{|c|c|c|c|c|c|c|}
\hline \multirow[t]{2}{*}{ Time } & \multirow[t]{2}{*}{ Immobilization (EC50) } & \multicolumn{5}{|l|}{$\operatorname{IC} 50(\mu \mathrm{g} / \mathrm{L})$} \\
\hline & & Swimming speed & Distance traveled & Heart rate & $\begin{array}{l}\text { Post- } \\
\text { abdominal } \\
\text { claw activity }\end{array}$ & $\begin{array}{l}\text { Thoracic limb } \\
\text { activity }\end{array}$ \\
\hline $24 \mathrm{~h}$ & $\begin{array}{l}19.8 \pm 0.3 \\
\quad(12.9-32.2)\end{array}$ & $\begin{array}{l}3.5 \pm 0.2 \\
\quad(1.1-11.6)\end{array}$ & $\begin{array}{l}3.3 \pm 0.2 \\
\quad(1.0-11.0)\end{array}$ & $\begin{array}{l}708 \pm 27 \\
\quad(162.0-1288.0)\end{array}$ & $\begin{array}{l}17.8 \pm 0.3 \\
\quad(1.4-34.3)\end{array}$ & $\begin{array}{l}2.8 \pm 0.7 \\
\quad(1.2-6.2)\end{array}$ \\
\hline $48 \mathrm{~h}$ & $\begin{array}{l}1.0 \pm 0.06 \\
\quad(0.02-16.6)\end{array}$ & $\begin{array}{l}0.4 \pm 0.07 \\
\quad(0.1-1.4)\end{array}$ & $\begin{array}{l}0.5 \pm 0.06 \\
\quad(0.1-1.5)\end{array}$ & $\begin{array}{l}4.5 \pm 0.3 \\
\quad(2.1-9.5)\end{array}$ & $\begin{array}{l}0.6 \pm 0.07 \\
\quad(0.03-5.8)\end{array}$ & $\begin{array}{l}1.6 \pm 0.1 \\
\quad(0.8-3.3)\end{array}$ \\
\hline $72 \mathrm{~h}$ & $\begin{array}{l}0.5 \pm 0.04 \\
\quad(0.2-0.7)\end{array}$ & $\begin{array}{l}0.2 \pm 0.1 \\
\quad(0.1-0.5)\end{array}$ & $\begin{array}{l}0.2 \pm 0.1 \\
\quad(0.1-0.5)\end{array}$ & $\begin{array}{l}0.2 \pm 0.1 \\
\quad(0.1-0.6)\end{array}$ & $\begin{array}{r}0.04 \pm 0.01 \\
\quad(0.01-0.1)\end{array}$ & $\begin{array}{r}0.09 \pm 0.01 \\
(0.4-1.4)\end{array}$ \\
\hline
\end{tabular}

Lower and upper 95\% confidence intervals are given in parentheses, $p<0.0001$

\section{Immobilization}

The results showed that Daphnia magna exposed to FIP showed concentration- and time-dependent immobilization
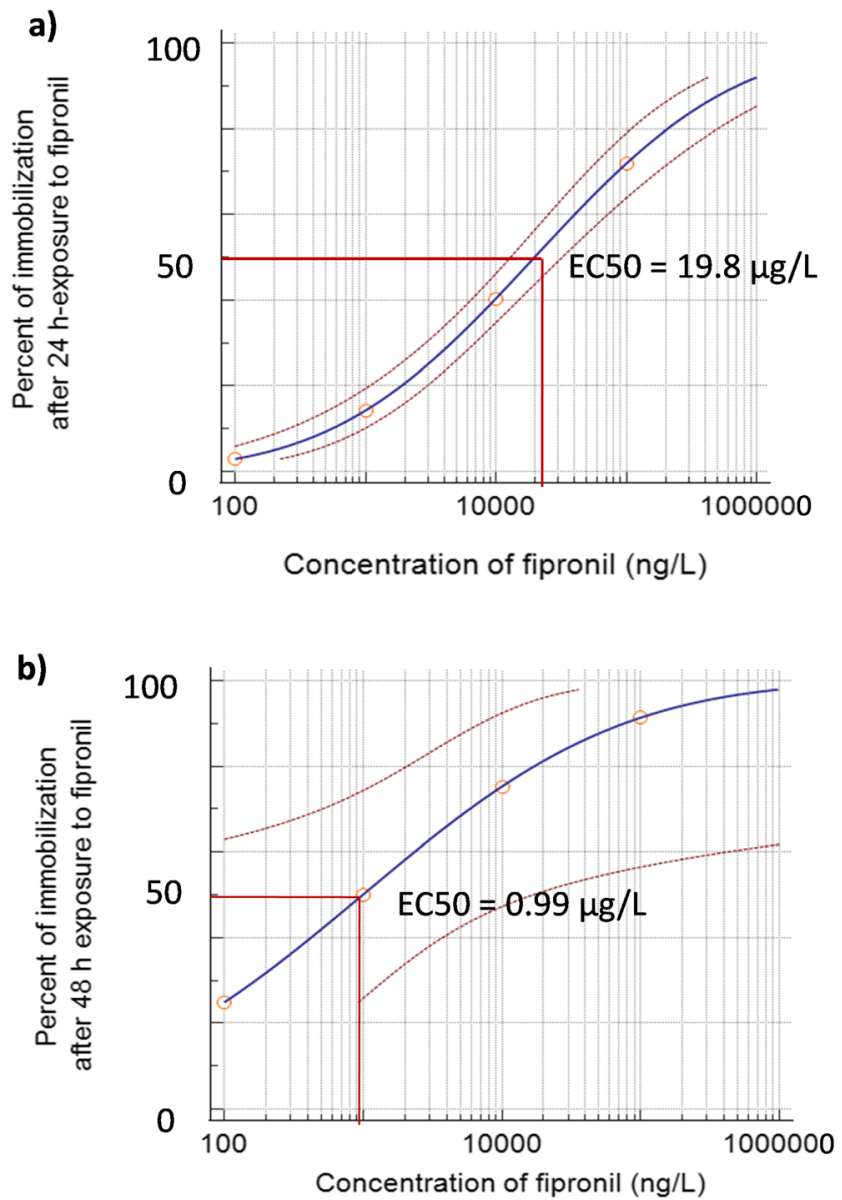

Fig. 1 Logarithmic curves of effective (nominal) concentration (EC50) 24-h (a) and 48-h exposure (b) for Daphnia magna immobilization after exposure to fipronil obtained by probit regression analysis. Gray vertical dashed lines represent logarithm scale of fipronil nominal concentration
(Fig. 2; Table 1). After $48 \mathrm{~h}$, immobilization was observed at all the concentrations of the compound use in the study $(30 \pm 5 \%, 50 \pm 5 \%, 60 \pm 9 \%$, and $100 \pm 9 \%$ at $0.1 \mu \mathrm{g} / \mathrm{L}, 1$ $\mu \mathrm{g} / \mathrm{L}, 10 \mu \mathrm{g} / \mathrm{L}$, and $100 \mu \mathrm{g} / \mathrm{L}$, respectively). The highest percentage of the immobilized animals was noted after $72 \mathrm{~h}$ of the exposure $(40 \pm 9 \%, 60 \pm 15 \%$, and $100 \pm 10 \%$ at $0.1 \mu \mathrm{g} / \mathrm{L}, 1$ $\mu \mathrm{g} / \mathrm{L}, 10 \mu \mathrm{g} / \mathrm{L}$, respectively).

\section{Swimming speed}

Effects of FIP on daphnids swimming speed are presented in Fig. 3. The result show that the insecticide induced a substantial decrease of daphnid swimming speed at all tested concentrations after $24 \mathrm{~h}(3.60 \pm 0.21 \mathrm{~mm} / \mathrm{s}, p<0.01 ; 2.95 \pm$ $0.20 \mathrm{~mm} / \mathrm{s}, p<0.01 ; 2.1 \pm 0.63 \mathrm{~mm} / \mathrm{s}, p<0.01 ; 2.0 \pm 0.20$ $\mathrm{mm} / \mathrm{s}, p<0.01$ at $0.1 \mu \mathrm{g} / \mathrm{L}, 1 \mu \mathrm{g} / \mathrm{L}, 10 \mu \mathrm{g} / \mathrm{L}, 100 \mu \mathrm{g} / \mathrm{L}$, respectively) when compared to the control $(5.32 \pm 0.22$ $\mathrm{mm} / \mathrm{s}$ ). More reduced parameter was found in the treated animals after $48 \mathrm{~h}$, and complete cessation of motility was noted in the crustaceans exposed to $100 \mu \mathrm{g} / \mathrm{L}$ after $48 \mathrm{~h}$ and $10 \mu \mathrm{g} / \mathrm{L}$ after $72 \mathrm{~h}$.

\section{Distance traveled}

Daphnids exposed to FIP showed a concentration- and timedependent reduction of distance traveled (Fig. 4). A distinct inhibition of this endpoint was noted after $24 \mathrm{~h}$ in the group of crustaceans treated with the lowest concentration of $0.1 \mu \mathrm{g} / \mathrm{L}$ $(216 \pm 37 \mathrm{~mm} / \mathrm{min} ; p<0.01)$ when compared to the control $(319 \pm 15 \mathrm{~mm} / \mathrm{min})$. The distance traveled was decreasing with the increasing time of exposure to FIP. No distance traveled was noted in daphnids at $100 \mu \mathrm{g} / \mathrm{L}$ after $48 \mathrm{~h}$ and at 10 $\mu \mathrm{g} / \mathrm{L}$ after $72 \mathrm{~h}$. 
Fig. 2 Immobilization (\%) of Daphnia magna exposed to various concentrations of fipronil. Results are presented as means \pm $\mathrm{SD}, n=15$; * - statistical significance when compared to the control at $* p<0.05 ; * * p<0.01$

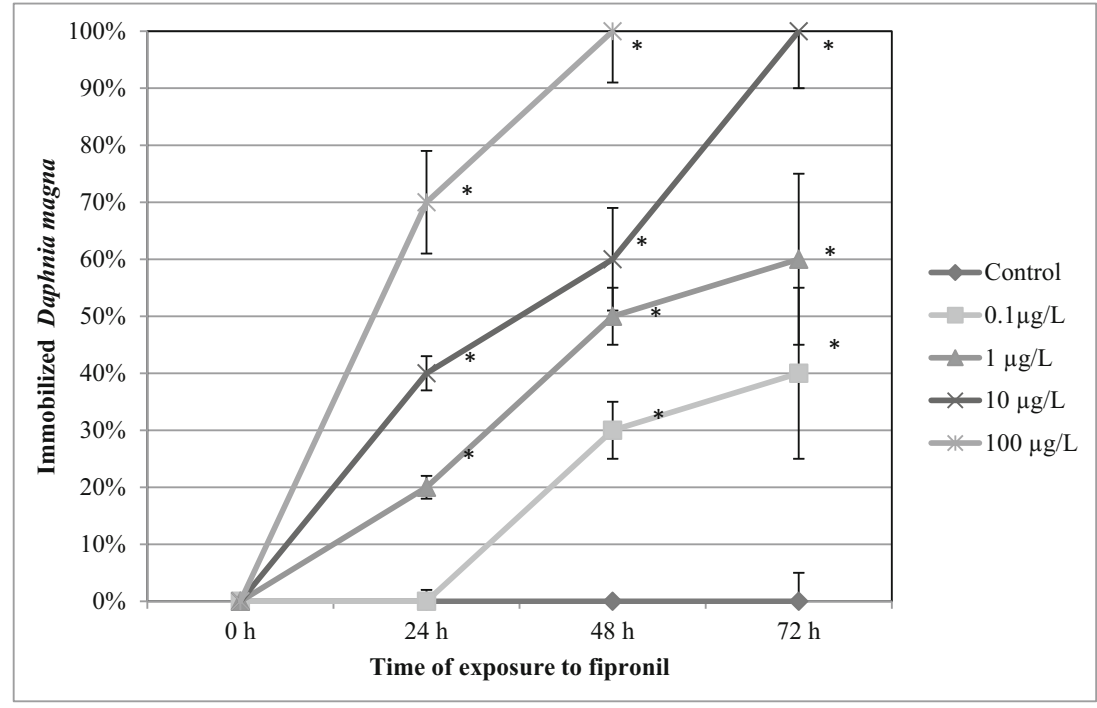

\section{Heart rate}

The results show that FIP at concentrations of $1 \mu \mathrm{g} / \mathrm{L}, 10$ $\mu \mathrm{g} / \mathrm{L}$, and $100 \mu \mathrm{g} / \mathrm{L}$ reduced daphnid heart rate after $24-\mathrm{h}$ exposure (172.2 \pm 25.7 beats per minute [bpm], $142 \pm 21.5$ bpm, $p<0.01$, and $124 \pm 26.6 \mathrm{bpm}, p<0.01$, respectively), when compared to the control (197.5 \pm 25.8 bpm) (Fig. 5). Further exposure resulted in more spectacular reduction of daphnid heart rate. After 72-h treatment with FIP, the endpoint was $110 \pm 21.8 \mathrm{bpm}$ at $0.1 \mu \mathrm{g} / \mathrm{L}, 73 \pm 13.9 \mathrm{bpm} p<0.01$ at 1 $\mu \mathrm{g} / \mathrm{L}$, and $0 \pm 0 \mathrm{bpm} p<0.01$ at $10 \mu \mathrm{g} / \mathrm{L}$ when compared to the control (180 $\pm 35 \mathrm{bpm})$.

\section{Post-abdominal claw activity}

The results presented in Fig. 6 show that FIP at a concentration of $0.1 \mu \mathrm{g} / \mathrm{L}$ induced a transient increase of post-abdominal claw activity. However, a decrease of this endpoint was found at concentrations of $10 \mu \mathrm{g} / \mathrm{L}(7.5 \pm 2.2 \mathrm{bpm} ; p<0.01)$ and 100 $\mu \mathrm{g} / \mathrm{L}(2.2 \pm 0.9 \mathrm{bpm} ; p<0.01)$ after 24 -h exposure when compared to the control $(11.5 \pm 2.5 \mathrm{bpm})$. The highest reduction of this physiological activity showed daphnids at 72 -h exposure to the pesticide ( $3 \pm 1.5 \mathrm{bpm}, p<0.01 ; 2 \pm 0.2$ bpm, $p<0.01$; and $0 \pm 0 \mathrm{bpm} p<0.01$ ) at concentrations of $0.1 \mu \mathrm{g} / \mathrm{L}, 1 \mu \mathrm{g} / \mathrm{L}, 10 \mu \mathrm{g} / \mathrm{L}$, respectively).
Fig. 3 Swimming speed of Daphnia magna exposed to various concentrations of fipronil. Results are presented as means \pm $\mathrm{SD}, n=15$; * - statistical significance when compared to the control at $* p<0.05 ; * * p<0.01$

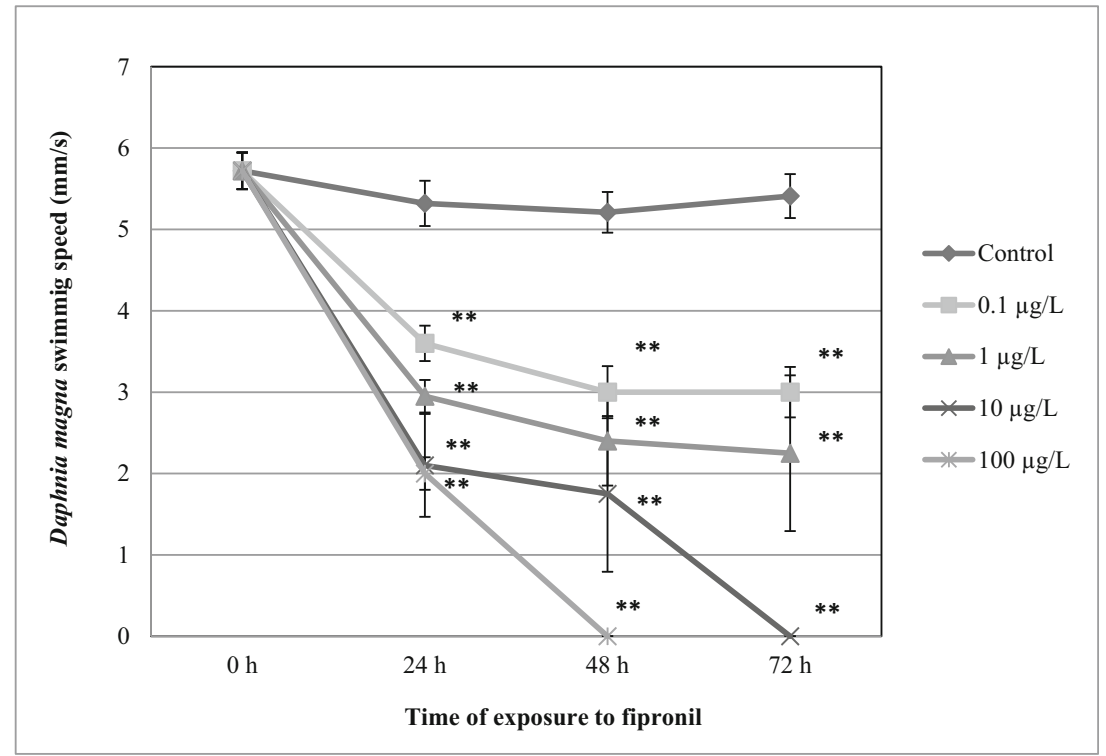


Fig. 4 Distance traveled by Daphnia magna during exposure to fipronil. Results are presented as means $\pm \mathrm{SD}, n=15$; * - statistical significance when compared to the control at $* p<0.05 ; * * p<$ 0.01

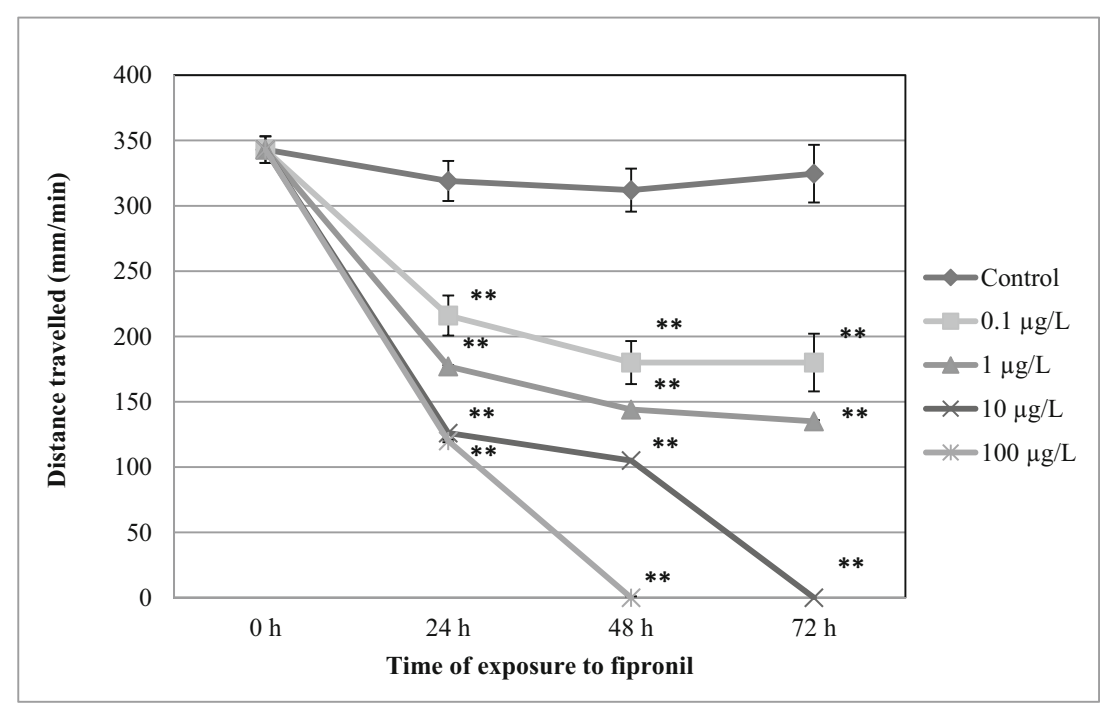

\section{Thoracic limb activity}

Figure 7 shows that the activity of daphnid thoracic limbs was increased significantly after $48 \mathrm{~h}$ of the exposure to FIP at a concentration of $0.1 \mu \mathrm{g} / \mathrm{L}(210 \pm 23 \mathrm{bpm})$ when compared to the control $(180 \pm 22 \mathrm{bpm})$. However, higher concentrations of the pesticide induced a concentration- and time-dependent decrease of this endpoint. More significant reduction was found in daphnids exposed to a concentration as low as 1 $\mu \mathrm{g} / \mathrm{L}(72 \pm 17 \mathrm{bpm}, p<0.01)$ both after $48 \mathrm{~h}(35 \pm 15 \mathrm{bpm}$, $p<0.01)$ and after $72 \mathrm{~h}$ of exposure.

\section{Discussion}

Little is known on sublethal effects of FIP in crustaceans. Lethal effects of FIP in crustaceans were documented by some authors. For example, it was revealed that the LC50 value after 48-h exposure of Daphnia pulex was estimated to be 0.0156 $\mathrm{mg} / \mathrm{L}$ (Stark and Vargas 2005). FIP was also found to be lethal to brown shrimp (Farfantepenaeus aztecus) (96-h LC50 = $0.12 \mu \mathrm{g} / \mathrm{L})$ (Al-Badran et al. 2019) and a marine grass shrimp Palaemonetes pugio $(96-\mathrm{h}$ LC50 $=0.32 \mu \mathrm{g} / \mathrm{L})$ (Overmyer et al. 2007). Some sublethal effects of FIP on Ceriodaphnia
Fig. 5 Heart rate of Daphnia magna exposed to fipronil. Results are presented as means \pm $\mathrm{SD}, n=15$; * - statistical significance when compared to the control at $* p<0.05 ; * * p<0.01$

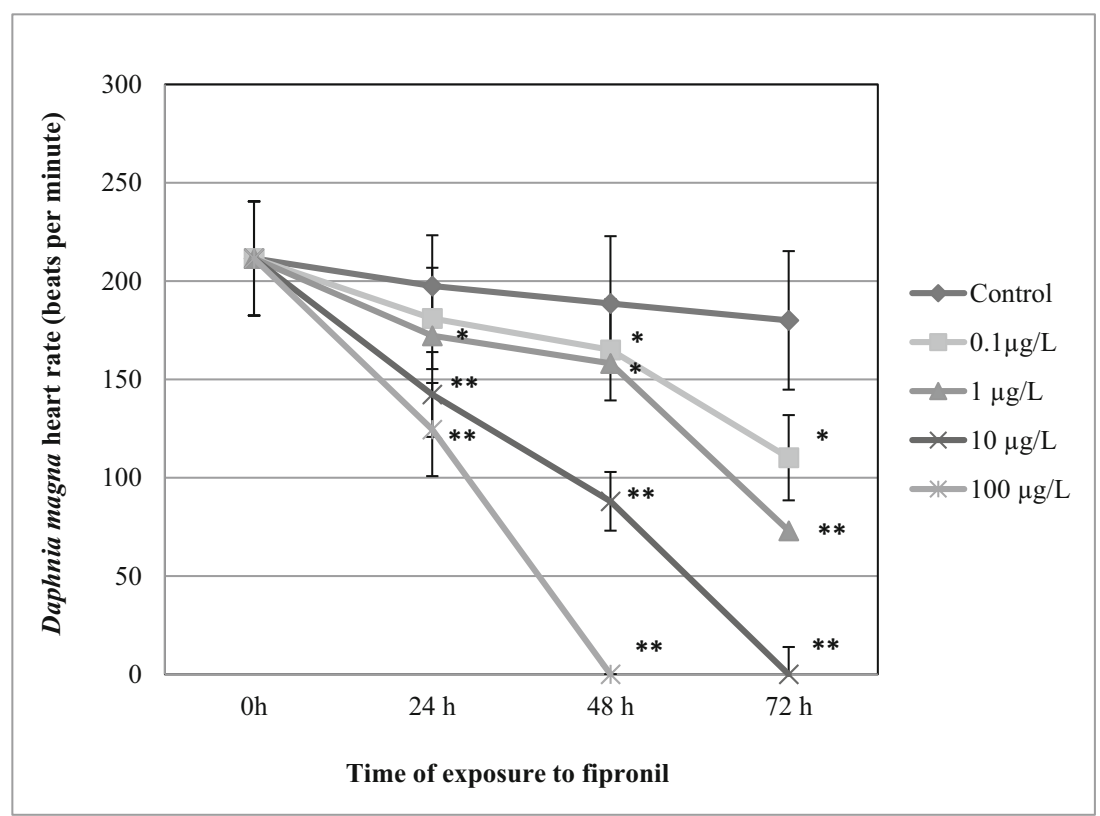


Fig. 6 Post-abdominal claw activity of Daphnia magna exposed to various concentrations of fipronil. Results are presented as means $\pm \mathrm{SD}, n=15$; * - statistical significance when compared to the control at $* p<0.05 ; * * p<$ 0.01

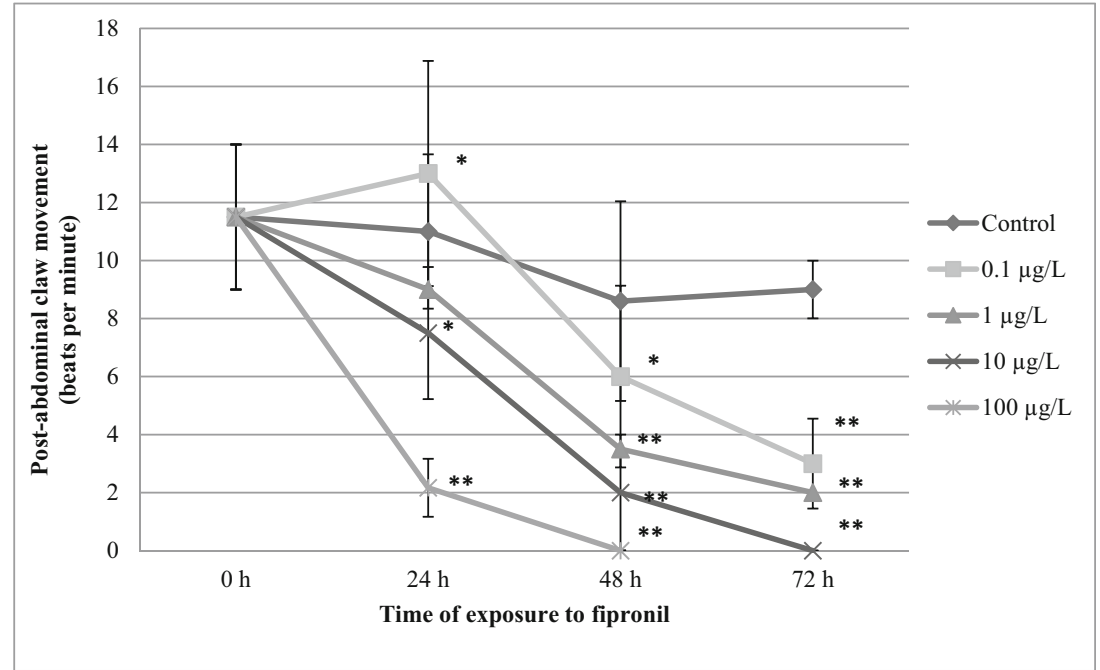

silvestrii life history traits, growth of brown shrimp Farfantepenaeus aztecus, and reproduction of copepods were also found (Cary et al. 2004; Al-Badran et al. 2019; Moreira et al. 2020). The present study showed that FIP induced toxic changes of Daphnia magna endpoints in a concentration- and time-dependent manner. Exposure of experimental animals to FIP resulted in immobilization observed after 24-h and 48-h exposure with nominal EC50 values of $19.8 \pm 0.3 \mu \mathrm{g} / \mathrm{L}$ and $1.0 \pm 0.06 \mu \mathrm{g} / \mathrm{L}$, respectively. Inhibition of daphnid motility was also observed by other authors; however, Hayasaka et al. (2012) found that higher concentration of FIP $(88.3 \mu \mathrm{g} / \mathrm{L})$ was required to induce 50\% immobilization of Daphnia magna after $48 \mathrm{~h}$ of exposure. Since pure analytical standard was used in the present experiments and a commercial formulation with an active ingredient in the study performed by Hayasaka et al. (2012), different EC50 values may result from different purities of FIP used in both experiments. Immobilization induced by FIP was also found in other cladocerans. However different EC50 values were obtained by various authors. Although 48-h EC50 of FIP were $0.99 \mu \mathrm{g} / \mathrm{L}$ and $8.83 \mu \mathrm{g} / \mathrm{L}$ for immobilization of Ceriodaphnia dubia and Ceriodaphnia reticulata, respectively (Hayasaka et al. 2012), Konwick et al. (2005) calculated the 48-h EC50 for Ceriodaphnia dubia to be as high as $10.3 \mu \mathrm{g} / \mathrm{L}$. Some authors documented sublethal effects were found in crustaceans such as male infertility decreased reproductive rate, birth rate an increase in generation time (Cary et al. 2004; Stark and Vargas 2005; Moreira et al. 2020). Our calculation of nominal IC50 for Daphnia magna showed that both behavioral and physiological endpoints are more sensitive to FIP than immobilization because the IC50 of behavioral parameters were much lower than EC50 for immobilization after $24 \mathrm{~h}$. Thoracic limb activity, swimming speed, and distance traveled turned out to be the most sensitive endpoints to FIP. Swimming speed was the most sensitive after 48 h. However, after $72 \mathrm{~h}$ of the exposure thoracic limb activity again showed the lowest IC50 value. Although heart rate was
Fig. 7 Thoracic limb activity of Daphnia magna exposed to various concentrations of fipronil. Results are presented as means \pm $\mathrm{SD}, n=15 ; *$ - statistical significance when compared to the control at $* p<0.05 ; * * p<0.01$

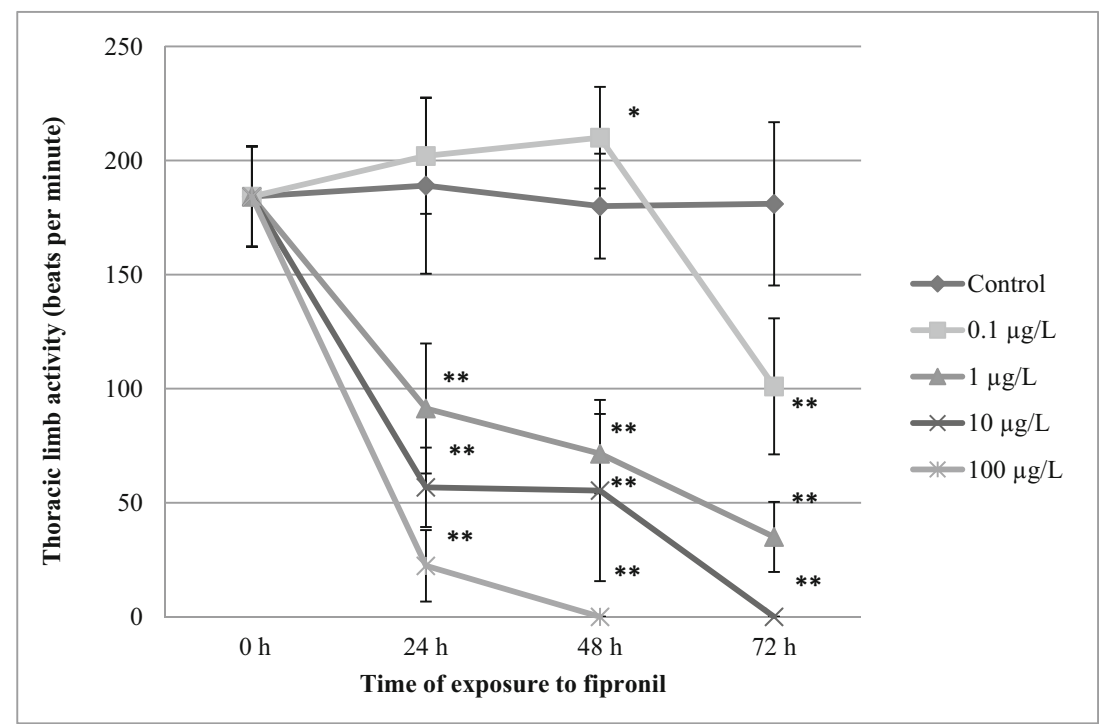


the least sensitive after $24 \mathrm{~h}$, the IC50 was comparable with the other endpoints after $72 \mathrm{~h}$.

This study showed that FIP induced a concentration- and time-dependent decrease of daphnid swimming speed which may be explained by neurotoxic activity of the pesticide. It is possible that blocking the GABA-regulated chloride channels in neurons resulted in overexcitation of neurons innervating daphnid muscles of second antennae responsible for swimming activity which led to spastic paralysis as it was found in insects (Hossie et al. 1995). Similar results were obtained by Al-Badran et al. (2018) who found reduction of locomotor activity in juvenile brown shrimp Farfantepenaeus aztecus with specific movement disturbances such as swimming in circles. Our results also seem to be in agreement with those obtained by Hussain et al. (2020) who demonstrated depression of Daphnia magna locomotor activity after the exposure to FIP at a concentration of $0.117 \mu \mathrm{g} / \mathrm{L}$. Alterations of motility was also noted in fish exposed to FIP; however, changes were associated with increased swimming activity (Gibbons et al. 2015; Wang et al. 2016; Hussain et al. 2020). The opposite effects on swimming behavior in Daphnia magna and fish may be attributed to differences in the mechanisms related with the release of neurotransmitters in synapses after direct interaction of FIP with receptors for GABA or glutamic acid (Zheng et al. 2014).

Distance traveled by daphnids is a behavioral parameter which indicated toxic effects induced by various agents (Jang et al. 2016; Bownik 2017). Our study showed that the distance traveled by the experimental animals was decreasing with increasing concentration of FIP which was manifested by the shorter tracks of daphnids exposed to the highest compound concentration when compared to the control. Similar results were obtained by Hussain et al. (2020) who noted reduction of distance traveled by Daphnia magna and zebrafish larvae exposed to FIP. Reduction of swimming distances clearly indicates that Daphnia neuromuscular system is sensitive to FIP. Decrease of this parameter was also observed in fish (Danio rerio) exposed to FIP (Wu et al. 2015). Behavioral disorders may have ecological consequences for cladocerans such as disturbances of vertical and horizontal migration and higher susceptibility to predators.

Daphnids have a transparent carapace allowing clear observation of heart physiological activity (Campbell et al. 2004). We found that FIP induced a concentration- and timedependent reduction of the number of heart contractions in Daphnia magna. It is possible that decrease of heart rate may result from a direct interaction of FIP with receptors for GABA and glutamic acid in neurons regulating daphnid cardiac activity. The knowledge on the effects of FIP on the activity of crustacean heart is scarce; however, some authors reported that this pesticide affects heart activity of bees (Nicodemo et al. 2014). The authors linked the disturbances of heart functioning with the inhibited mitochondrial activity resulting from ATP depletion. Toxicity of heart mitochondria by FIP were also found in rats (Seydi et al. 2019). On the basis of the above-mentioned studies, it may be hypothesized that disturbances of daphnid heart rate may be a result of mitochondrial dysfunctions. FIP was also noted to induce cardiotoxic changes in zebrafish larvae such as heart beat irregularity and disruption of blood vessel formation (Park et al. 2020). Dysfunctions of heart activity in Daphnia magna may have serious physiological consequences such as depressed hemolymph circulation.

Daphnid post-abdominal claw is an organ which removes the excess of particles absorbed by thoracic limbs (Young et al. 1997). Some results indicated that its activity may be altered by toxic chemicals at sublethal levels (Lovern et al. 2007; Bownik and Pawlik-Skowrońska 2019). Our study showed that FIP at the lowest concentration increased the post-abdominal claw activity after $24 \mathrm{~h}$. This hormetic effects may be explained by the fact that lower concentrations of FIP may trigger slight neurostimulation related with increased activity of excitatory neurotransmitters. On the other hand, higher concentrations of FIP may evoke overexcitation of neuron innervating muscles of the post-abdominal claw leading to muscle paralysis (Pisa et al. 2015). Exposure of daphnids to FIP in natural conditions may lead to disturbances of feeding.

Thoracic limbs play an important role in daphnid feeding and ventilation (Pirow et al. 1999). Rhythmic beating of these appendages forms water currents carrying food and providing oxygen to the organism (Lari et al. 2017). Thoracic limb activity is a valuable toxicological endpoint useful in recognition of early signs of behavioral and physiological disorders induced by various detrimental factors (Lari et al. 2017; Bownik et al. 2019a, b). Little is known about the effects of FIP on thoracic limb activity of cladocerans; however, some authors revealed other insecticides such as lambdacyhalothrin (Bownik et al. 2019a) or cypermethrin (FribergJensen et al. 2010) may alter functioning of this organ. The present study showed that the lowest concentration of FIP increased the activity of thoracic limb movement. On the other hand, higher levels of the pesticide decreased the number of beats. The mechanism of depressive effects of FIP on thoracic limb activity may be related with overexcitation of neurons innervating daphnid thoracic limbs leading to excessive appendage muscle contraction. Since thoracic limbs are vital for daphnid feeding and ventilation, disturbances in functioning of these organs may affect food and oxygen supply. Natural exposure to FIP may be one of factors inducing disturbances in water filtration implicating the increase of the remaining biomass (bacteria, algae, protozoans) in aquatic reservoirs. The consequence of this phenomenon may be increased water turbidity. Ventilation deficits resulting from daphnid exposure to FIP may inhibit oxygen supply leading to hypoxia, metabolic disorders, and physiological and behavioral 
disturbances. Although little is known on the effects of FIP on cladoceran feeding activity in cladocerans, some authors found reduction of feeding ability in dragonflies (Sympetrum spp.) (Jinguji et al. 2018).

\section{Concluding remarks}

The present study showed that daphnid behavioral and physiological endpoints are sensitive indicators of toxic changes induced by FIP; however, sensitivity of these responses was different at various times of exposure. Since FIP induced alterations of daphnid endpoints at environmentally relevant concentrations, it may be expected that vital behavioral and physiological processes may be impaired by this pesticide in the real scenario. More studies in daphnids are required that would provide results useful in explanation of the neurological mechanisms responsible for the behavioral and physiological alterations.

Author contribution $\mathrm{AB}$ formulated the goals of the study, analyzed and interpreted the data, and wrote, edited, and formatted the manuscript.

AS performed the experiments, analyzed data with computer software, and wrote the first version of the manuscript.

Availability of data and materials The datasets used and/or analyzed during the current study are available from the second author on the reasonable request.

\section{Declarations}

Ethics approval and consent to participate Not applicable.

Consent for publication Not applicable.

Competing interests The authors declare no competing interests

Open Access This article is licensed under a Creative Commons Attribution 4.0 International License, which permits use, sharing, adaptation, distribution and reproduction in any medium or format, as long as you give appropriate credit to the original author(s) and the source, provide a link to the Creative Commons licence, and indicate if changes were made. The images or other third party material in this article are included in the article's Creative Commons licence, unless indicated otherwise in a credit line to the material. If material is not included in the article's Creative Commons licence and your intended use is not permitted by statutory regulation or exceeds the permitted use, you will need to obtain permission directly from the copyright holder. To view a copy of this licence, visit http://creativecommons.org/licenses/by/4.0/.

\section{References}

Aajoud A, Ravanel P, Tissut M (2003) Fipronil metabolism and dissipation in a simplified aquatic ecosystem. J Agric Food Chem 51:13471352
Al-Badran AA, Fujiwara M, Gatlin DM 3rd, Mora MA (2018) Lethal and sub-lethal effects of the insecticide fipronil on juvenile brown shrimp Farfantepenaeus aztecus. Sci Rep 17:10769

Al-Badran AA, Fujiwara M, Mora MA (2019) Effects of insecticides, fipronil and imidacloprid, on the growth, survival, and behavior of brown shrimp Farfantepenaeus aztecus. PLoS One 14:e0223641

American Society of Testing and Materials (1986) Standard practice for conducting static acute toxicity tests on wastewaters with Daphnia: Annual book of ASTM standards. ASTM. Vol. 11.04. Philadelphia, D4229-D4284

Apenet (2011) Effects of coated maize seed on honey bees. Report based on results obtained from the third year activity of the apenet project

Ardeshir RA, Zolgharnein H, Movahedinia A, Salamat N, Zabihi E (2017) Comparison of waterborne and intraperitoneal exposure to fipronil in the Caspian white fish (Rutilus frisii) on acute toxicity and histopathology. Toxicol Rep 4:348-357

Bevilaqua F, Sachett A, Chitolina R, Garbinato C, Gasparetto H, Marcon M, Siebel AM (2020) A mixture of fipronil and fungicides induces alterations on behavioral and oxidative stress parameters in zebrafish. Ecotoxicology 29:140-147

Bloomquist JR (2003) Chloride channels as tools for developing selective insecticides. Arch Insect Biochem Physiol 54:145-156

Bonmatin JM, Giorio C, Girolami V, Goulson D, Kreutzweiser DP, Krupke C, Noome DA (2015) Environmental fate and exposure; neonicotinoids and fipronil. Environ Sci Pollut Res 22:35-67

Bownik A (2017) Daphnia swimming behavior as a biomarker in toxicity assessment: a review. Sci Total Environ 601-602:194-205

Bownik A, Pawlik-Skowrońska B (2019) Early indicators of behavioral and physiological disturbances in Daphnia magna (Cladocera) induced by cyanobacterial neurotoxin anatoxin-a. Sci Total Environ 695:133913

Bownik A, Kowalczyk M, Bańczerowski J (2019a) Lambda-cyhalothrin affects swimming activity and physiological responses of Daphnia magna. Chemosphere 216:805-811

Bownik A, Szabelak A, Kulińska M, Wałęka M (2019b) Effects of Lproline on swimming parameters of Daphnia magna subjected to heat stress. J Them Biol 84:154-163

Bownik A, Ślaska B, Dudka J (2020a) Cisplatin affects locomotor activity and physiological endpoints of Daphnia magna. J Hazard Mater 384:121259

Bownik A, Jasieczek M, Kosztowny E (2020b) Ketoprofen affects swimming behavior and impairs physiological endpoints of Daphnia magna. Sci Total Environ 725:138312

Campbell AK, Wann KT, Matthews SB (2004) Lactose causes heart arrhythmia in the water flea Daphnia pulex. Comp Biochem Physiol B: Biochem Mol Biol 139:225-234

Cary LT, Chandler GT, Volz DC, Walse SS, Ferry JL (2004) Phenylpyrazole insecticide fipronil induces male infertility in the estuarine meiobenthic crustacean Amphiascus tenuiremis. Environ Sci Technol 38:522-528

Chandler GT, Carry TL, Volz DC, Walse SS, Ferry JL, Klosterhaus SL (2004) Fipronil effects on estuarine copepod (Amphiascus tenuiremis) development, fertility, and reproduction: a rapid lifecycle assay in 96-well microplate format. Environ Toxicol Chem 23:117-124

Charalampous AC, Liapis KS, Bempelou ED (2019) Fipronil in eggs. Is LC-MS/MS the only option? A comparison study of LC-MS/MS and GC-ECD for the analysis of fipronil. Chromatogr B Analyt Technol Biomed Life Sci 1129:121785

Demcheck DK, Skrobialowski SC (2003) Fipronil and degradation products in the rice-producing areas of the Mermantau river basin, Louisiana, February-September 2000. Fact Sheet FS-010-03. National Water Quality Assessment Program. U.S.G.S. Baton Rouge, LA

Ensminger M, Budd R, Kelley KC, Goh KS (2013) Pesticide occurrence and aquatic benchmark exceedances in urban surface waters and 
sediments in three urban areas of California, USA, 2008-2011. Environ Monit Assess 185:3697-3710

European Food Safety Authority (EFSA), Reich H, Triacchini GA (2018) Occurrence of residues of fipronil and other acaricides in chicken eggs and poultry muscle/fat. EFSA J 16:e05164

Friberg-Jensen U, Nachman G, Christoffersen KS (2010) Early signs of lethal effects in Daphnia magna (Branchiopoda, Cladocera) exposed to the insecticide cypermethrin and the fungicide azoxystrobin. Environ Toxicol Chem 29:2371-2378

Gan J, Bondarenko S, Oki L, Haver D, Li JX (2012) Occurrence of fipronil and its biologically active derivatives in urban residential runoff. Environ Sci Technol 46:1489-1495

Gibbons D, Morrissey C, Mineau P (2015) A review of the direct and indirect effects of neonicotinoids and fipronil on vertebrate wildlife. Environ Sci Pollut Res 22:103-118

Goff AD, Saranjampour P, Ryan LM, Hladik ML, Covi JA, Armbrust KL, Brander SM (2017) The effects of fipronil and the photodegradation product fipronil desulfinyl on growth and gene expression in juvenile blue crabs, Callinectes sapidus, at different salinities. Aquat Toxicol 186:96-104

Gunasekara AS, Truong T, Goh KS, Spurlock F, Tjeerdema RS (2007) Environmental fate and toxicology of fipronil. J Pest Sci 32:189199

Hano T, Ito K, Ohkubo N, Sakaji H, Watanabe A, Takashima K, Sato T, Sugaya T, Matsuki K, Onduka T, Ito M, Somiya R, Mochida K (2019) Occurrence of neonicotinoids and fipronil in estuaries and their potential risks to aquatic invertebrates. Environ Pollut 252: 205-215

Hatta S, Odagawa Y, Izumi J, Nakamae S (2019) Study on fipronil and other pesticide residues in chicken eggs produced and sold in Japan. Shokuhin Eiseigaku Zasshi 60:154-158

Hayasaka D, Korenaga T, Suzuki K, Sánchez-Bayo F, Goka K (2012) Differences in susceptibility of five cladoceran species to two systemic insecticides, imidacloprid and fipronil. Ecotoxicology 21: $421-427$

Holder PJ, Jones A, Tyler CR, Cresswell JE (2018) Fipronil pesticide as a suspect in historical mass mortalities of honey bees. Proc Natl Acad Sci U S A 115:13033-13038

Hossie AM, Baylis HA, Buckingham SD, Sattelle DB (1995) Actions of the insecticide fipronil, on dieldrin-sensitive and- resistant GABA receptors of Drosophila melanogaster. Br J Pharmacol 115:909915

Huang Y, Campana O, Wlodkowic D (2017) A millifluidic system for analysis of Daphnia magna locomotory responses to water-born toxicants. Sci Rep 7:17603

Huang Y, Cartlidge R, Walpitagama M, Kaslin J, Campana O, Wlodkowic D (2018) Unsuitable use of DMSO for assessing behavioral endpoints in aquatic model species. Sci Total Environ 615: $107-114$

Hussain A, Audira G, Malhotra N, Uapipatanakul B, Chen JR, Lai YH, Hsiao CD (2020) Multiple screening of pesticides toxicity in Zebrafish and Daphnia based on locomotor activity alterations. Biomolecules 10:1224

Jang GH, Park C-B, Kang BJ, Kim YJ, Lee K (2016) Sequential assessment via Daphnia and zebrafish for systematic toxicity screening of heterogeneous substances. Environ Pollut 216:292-303

Jinguji H, Ohtsu K, Ueda T, Goka K (2018) Effects of short-term, sublethal fipronil and its metabolite on dragonfly feeding activity. PLoS One 13:e0200299

Key PB, Chung KW, Opatkiewicz AD, Wirth EF, Fulton MH (2003) Toxicity of the insecticides fipronil and endosulfan to selected life stages of the grass shrimp (Palaemonetes pugio). Bull Environ Contam Toxicol 70:533-540

Konwick BJ, Fisk AT, Garrison AW, Avants JK, Black MC (2005) Acute enantioselective toxicity of fipronil and its desulfinyl photoproduct to Ceriodaphnia dubia. Environ Toxicol Chem 24:2350-2355
Lari E, Steinkey D, Pyle GG (2017) A novel apparatus for evaluating contaminant effects on feeding activity and heart rate in Daphnia spp. Ecotoxicol Environ Saf 135:381-386

Lovern SB, Strickler JR, Klaper R (2007) Behavioral and physiological changes in Daphnia magna when exposed to nanoparticle suspensions (titanium dioxide, nano-C60, and $\mathrm{C} 60 \mathrm{HxC} 70 \mathrm{Hx}$ ). Environ Sci Technol 41:4465-4470

Macbean C (ed) (2012) ePesticide Manual. 15th ed., ver. 5.1, Alton, UK; British Crop Protection Council. Fipronil (120068-37-3)

MacLachlan DJ (2008) Transfer of fat-soluble pesticides from contaminated feed to poultry tissues and eggs. Br Poult Sci 49:290-298

Michel N, Freese M, Brinkmann M, Pohlmann JD, Hollert H, Kammann U, Hanel R (2016) Fipronil and two of its transformation products in water and European eel from the river Elbe. Sci Total Environ 568: $171-179$

Monteiro HR, Pestana JLT, Novais SC, Leston S, Ramos F, Soares AMVM, Devreese B, Lemos MFL (2019) Assessment of fipronil toxicity to the freshwater midge Chironomus riparius: molecular, biochemical, and organismal responses. Aquat Toxicol 216:105292

Moreira RA, Rocha O, Pinto TJDS, da Silva LCM, Goulart BV, Montagner CC, Espindola ELG (2020) Life-history traits response to effects of fish predation (kairomones), fipronil and 2,4-D on neotropical cladoceran Ceriodaphnia silvestrii. Arch Environ Contam Toxicol 79:298-309

Ngim KK, Crosby DG (2001) Abiotic processes influencing fipronil and desthiofipronil dissipation in California, USA, rice fields. Environ Toxicol Chem 20:972-977

Nicodemo D, Maioli MA, Medeiros HC, Guelfi M, Balieira KV, De Jong D, Mingatto FE (2014) Fipronil and imidacloprid reduce honeybee mitochondrial activity. Environ Toxicol Chem 33:2070-2075

Overmyer JP, Rouse DR, Avants JK, Garrison AW, Delorenzo ME, Chung KW, Key PB, Wilson WA, Black MC (2007) Toxicity of fipronil and its enantiomers to marine and freshwater non-targets. J Environ Sci Health B 42:471-480

Park H, Lee JY, Park S, Song G, Lim W (2020) Developmental toxicity of fipronil in early development of zebrafish (Danio rerio) larvae: Disrupted vascular formation with angiogenic failure and inhibited neurogenesis. J Hazard Mater 385:121531

Persoone G, Baudo R, Cotman M, Blaise C, Thompson KC, MoreiraSantos M, Vollat B, Törökne A, Han T (2009) Review on the acute Daphnia magna toxicity test - evaluation of the sensitivity and the precision of assays performed with organisms from laboratory cultures or hatched from dormant eggs. Knowl Manag Aquat Ecosyst 393:01

Pirow R, Wollinger F, Paul RJ (1999) The sites of respiratory gas exchange in the planktonic crustacean Daphnia magna: an in vivo study employing blood haemoglobin as an internal oxygen probe. J Exp Biol 202:3089-3099

Pisa LW, Amaral-Rogers V, Belzunces LP, Bonmatin JM, Downs CA, Goulson D, Morrissey CA (2015) Effects of neonicotinoids and fipronil on non-target invertebrates. Environ Sci Pollut Res 22:68 102

Ruby A (2013) Review of pyrethroid, fipronil and toxicity monitoring data from California urban watersheds. California Stormwater Quality Association (CASQA). $90 \mathrm{p}$

Rust MK (2017) The biology and ecology of cat fleas and advancements in their pest management: A Review. Insects 27:118

Scarampella F, Pollmeier M, Visser M, Boeckh A, Jeannin P (2005) Efficacy of fipronil in the treatment of feline cheyletiellosis. Vet Parasitol 129:333-339

Schlenk D, Huggett DB, Allgood J, Bennett E, Rimoldi J, Beeler AB (2001) Toxicity of fipronil and its degradation products to Procambarus sp.: field and laboratory studies. Arch Environ Contam Toxicol 41:325-332 
Seydi E, Mehrpouya L, Sadeghi H, Rahimi S, Pourahmad J (2019) Toxicity of fipronil on rat heart mitochondria. Toxin Rev In press: $1-9$

Simon-Delso N (2014) Systemic insecticides (neonicotinoids and fipronil): trends, uses, mode of action and metabolites. Environ Sci Pollut Res 22:5-34

Stark JD, Vargas RI (2005) Toxicity and hazard assessment of fipronil to Daphnia pulex. Ecotoxicol Environ Saf 62:11-16

Stehr CM, Linbo TL, Incardona JP, Scholz NL (2006) The developmental neurotoxicity of fipronil: notochord degeneration and locomotor defects in zebrafish embryos and larvae. Toxicol Sci 92:270-278

Stollewerk A (2010) The water flea Daphnia - a 'new' model system for ecology and evolution? J Biol 9:21

Stone WW, Gilliom RJ, Ryberg KR (2014) Pesticides in U.S. streams and rivers: occurrence and trends during 1992-2011. Environ Sci Technol 48:11025-11030

Tingle CCD, Rother JA, Dewhurst CF, Lauer S, King RP (2003) Fipronil: environmental fate, ecotoxicology, and human health concerns. Rev Environ Contam Toxicol 176:1-66

Tomlin C (ed) (1994) The pesticide manual (Crop Protection Publications/ British Crop Protection Council), Farnham, UK, pp 463

U.S. Geological Survey (2006) Fipronil. https://www.usgs.gov/scienceexplorer-results?es=fipronl. Accessed 10 Nov 2020

Van Poucke S, Creighton R, Baker AS (2016) Megninia ginglymura feather mite infestation in a Hamburg poultry flock in the United Kingdom. Vet Dermatol 27:127-9e35

Wang C, Qian Y, Zhang X, Chen F, Zhang Q, Li Z, Zhao M (2016) A metabolomic study of fipronil for the anxiety-like behavior in zebrafish larvae at environmentally relevant levels. Environ Pollut 211:252-258

Weston DP, Lydy MJ (2014) Toxicity of the insecticide fipronil and its degradates to benthic macroinvertebrates of urban streams. Environ Sci Technol 48:1290-1297
Wirth EF, Pennington PL, Lawton JC, DeLorenzo ME, Bearden D, Shaddrix B, Sivertsen S, Fulton MH (2004) The effects of the contemporary-use insecticide (fipronil) in an estuarine mesocosm. Environ Pollut 131:365-371

Wu H, Gao C, Guo Y, Zhang Y, Zhang J, Ma E (2014) Acute toxicity and sublethal effects of fipronil on detoxification enzymes in juvenile zebrafish (Danio rerio). Pestic Biochem Physiol 115:9-14

Wu J, Lu J, Lu H, Lin Y, Wilson PC (2015) Occurrence and ecological risks from fipronil in aquatic environments located within residential landscapes. Sci Total Environ 518-519:139-147

Xu H, Liu X, Jia Y, Dong F, Xu J, Wu X, Yang Y, Zheng Y (2018) Fipronil-induced toxic effects in zebrafish (Danio rerio) larvae by using digital gene expression profiling. Sci Total Environ 639:550 559

Young S, Palm M, Grover JP, McKee D (1997) How Daphnia cope with algae selected for inedibility in long running microsystems. J Plankton Res 19:391-397

Zhang Y, Ma J, Shi L, Cao D, Quan X (2016) Joint toxicity of cadmium and SDBS on Daphnia magna and Danio rerio. Ecotoxicology 10: 1703-1711

Zhang B, Zhang L, He L, Yang X, Shi Y, Liao S, Yang S, Cheng J, Ren T (2018) Interactions of fipronil within fish and insects: experimental and molecular modeling studies. J Agric Food Chem 66:5756-5761

Zheng N, Cheng J, Zhang W, Li W, Shao X, Xu Z, Xu X, Li Z (2014) Binding difference of fipronil with GABAARs in fruitfly and zebrafish: insights from homology modeling, docking, and molecular dynamics simulation studies. J Agric Food Chem 62:1064610653

Publisher's note Springer Nature remains neutral with regard to jurisdictional claims in published maps and institutional affiliations. 